\title{
Introduction of System of Rice Intensification (SRI) in Tribal Area of Chhindwara of (M.P)
}

\author{
Ghanshyam Deshmukh $^{1}$, S.L. Alawa ${ }^{2}$ and R.K. Jhade ${ }^{2}$ \\ ${ }^{1}$ COA, Balaghat, (M.P.), India \\ ${ }^{2} J N K V V, K V K$, Chhindwara, (M.P.), India \\ College of Agriculture, JNKVV Balaghat, (M.P.), India \\ *Corresponding author
}

\section{A B S T R A C T}

\section{Keywords}

SRI, B:C Ratio, Kharif, ATMA, Productivity

Article Info

Accepted:

10 March 2019

Available Online:

10 April 2019
System of rice intensification (SRI) is the new technology of rice production. First time in Chhindwara district of MP, SRI technique was introduced among tribal farmers. It was observed that average productivity in SRI was found $35.54 \mathrm{qt} \mathrm{ha}^{-1}$ as compared to District average productivity of $22.5 \mathrm{qt} \mathrm{ha}^{-1}$. Average input cost of cultivation was Rs $15127.68 \mathrm{ha}^{-1}$ and outcome was Rs $42796.25 \mathrm{ha}^{-1}$ and benefit cost ratio increases from 2.1 to 2.72 .

\section{Introduction}

More than half of humanity RICE IS LIFE. It is the grain that has shaped the livelihood, cultures, diets and economics of billions of people in Asia. For them, life and livelihood without rice is simply unthinkable. Rice is the staple food for $65 \%$ of the total population. The System of Rice Intensification (SRI) demonstrated that by changing the soil water and nutrient management the yield in rice can be increased by about $50 \%$ or more (Lin et al., 2005, 2006), while reducing water requirements by an equivalent percent. This gives farmers incentives to experiment with
SRI method, which also reduces the cost of production and increases their net income per ha by even more than yield. This benefit to the farmer is more than the contribution of increased yields (Satyanarayana et al., 2006). In the SRI method, it is to understand that it is merely a set of changes in managing paddy plants, soil, water and nutrients that can help increase the productivity. This change by using small farm implements and in the management of plants, soil, water and nutrients contribute to both healthier soil and plant supported by greater root growth and the nurturing of soil microbial abundance and diversity. It is based on a number of agro- 
ecological principles with good scientific foundations. Little capital is needed since SRI does not require purchasing new seeds or agrochemical inputs, only a line marker (for marking lines at well puddle field) and a Weeder which makes weeding more effective, as it contributes to soil aeration as well as the removal of weeds (Chaturvedi et al., 2006). Experience with SRI methods suggests that average rice yields can be about double the present world average without requiring a change in cultivar or the use of purchased inputs (Wang et al., 2002). Present study was carried out in the rice growing tribal area for study the mechanization on SRI (System of Rice Intensification).

\section{Materials and Methods}

\section{Scenario of SRI in the district}

At present around 30000 ha area under rice cultivation in the Chhindwara district of (M.P.). Most of the farmer of tribal area in the district cultivating rice crop by traditional methods of sowing i.e. broadcasting and line sowing. Productivity of rice in the area is very poor due using old local verities, high infestation of weeds, imbalance use of fertilizer and poor crop management practices. Productivity of rice in the area is 18 to $20 \mathrm{q} \mathrm{ha}^{-1}$.

\section{Need and importance SRI in the district}

Soybean and Maize are the major kharif crops in the district but last few years productivity of soybean is decreasing due following reasons:

Uncertainty of rainfall

Low productivity of local varieties

Improper use of fertilizer and nutrients

Limited use of mechanization
So, it is need to introduce new crop for the area to fill the vacuumed of soybean in kharif season. Krishi Vigyan Kendra, Chhindwara introduced SRI techniques with 50 farmers in the year 2012, 250 farmers in 2013, 325 farmers in 2014 and 350 farmers target in the year 2015 with ATMA. There are number of short to medium duration varieties available of rice. Some commonly recommended short to medium duration varieties are as under:

MTU 1010, 110 days old variety

WGL 32100, 115 days old variety

PS 5- 120, days old variety

JRH 5-100, days old variety

IR 64-110, days old variety

\section{Technology interventions and performance with economics}

JNKVV, Krishi Vigyan Kendra, Chhindwara first time introduced the SRI in the district with small land holding farmers of tribal community. Main focuses for SRI were as under:

Use of good quality seed (Breeder seed)/ seed replacement Seed treatment with fungicides

Proper nursery management avoid seed loss Use of line marker marking 25 X $25 \mathrm{~cm}$ plant to plant and row to row spacing

Transplanting 14-18 days old seedlings per plant per hill

Use of Rotary weeder for intercultural and weeding operation

Balance dose of nutrients and fertilizers

\section{Results and Discussion}

On the base of field data collected and collected data of more than 120 farmers engaging in SRI. Following calculations were drawn as under (Fig. 1-6 and Table 1). 
Table.1 Production and economic analysis of SRI in Chhindwara

\begin{tabular}{|c|c|c|c|c|}
\hline Number of farmer & Area, ha & $\begin{array}{c}\text { Average number of } \\
\text { tillers }\end{array}$ & Productivity, q/ha & B:C ratio \\
\hline $\mathbf{1 2 0}$ & 60 & 24 & 34.54 & 2.72 \\
\hline
\end{tabular}

Fig.1\&2 Puddling with power tiller \& line marking 25X $25 \mathrm{~cm}$
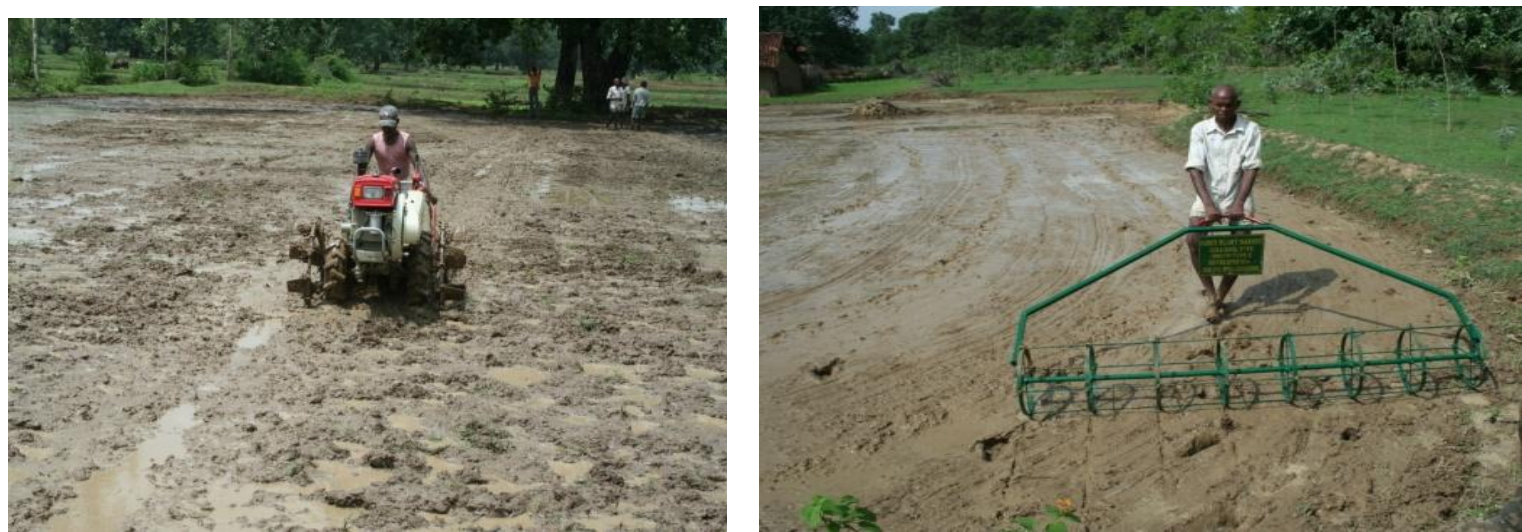

Fig.3\&4 Nursery for SRI \& Transplanting single seedling
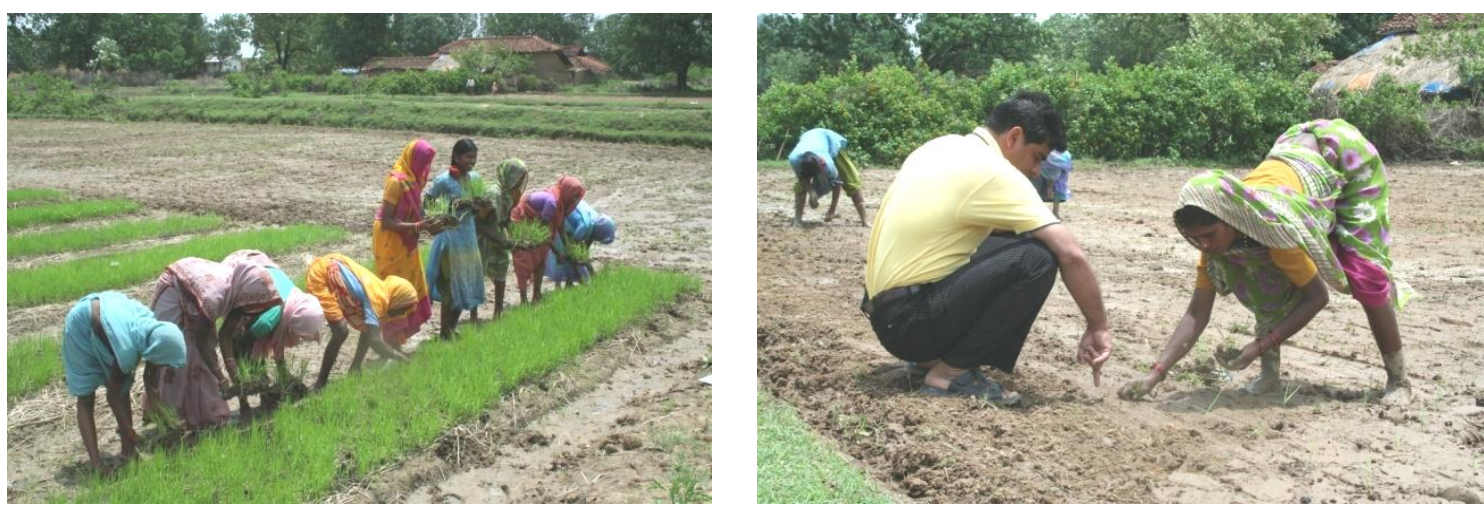

Fig.5\&6 Weeding through rotary weeder \& Observation of tillers
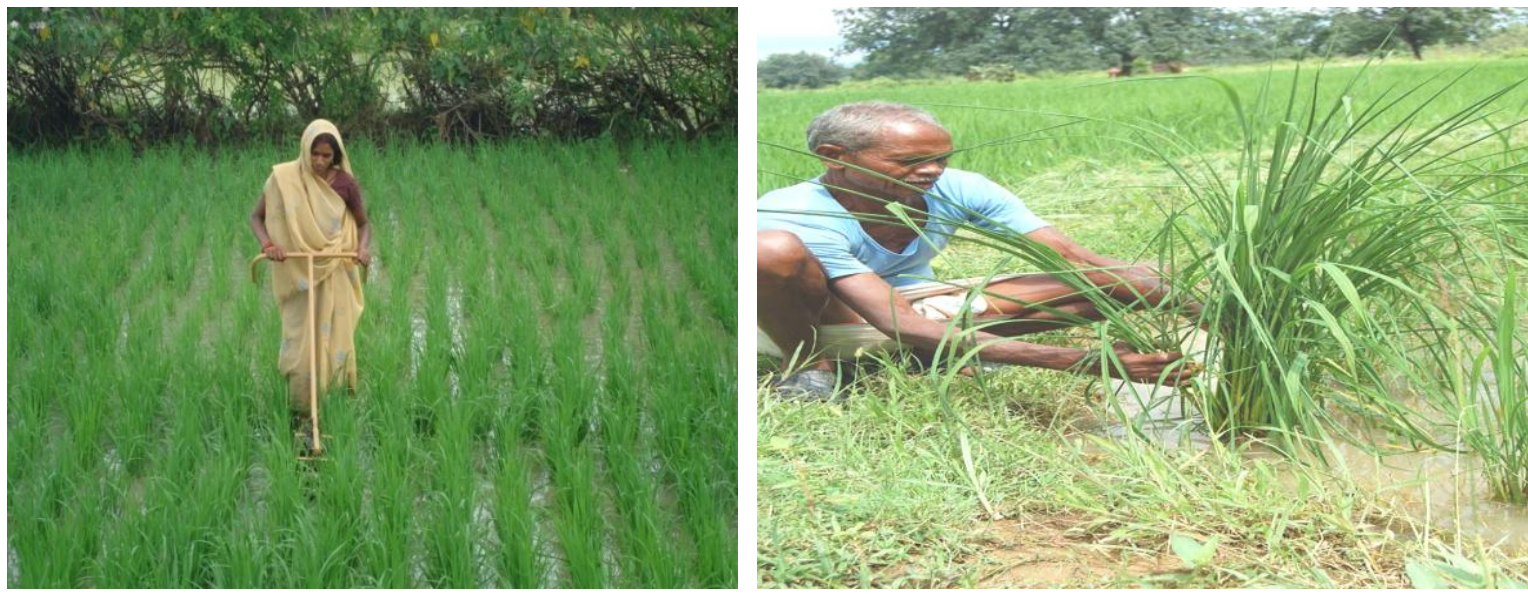
It was observed that average productivity in SRI was found $35.54 \mathrm{qt} \mathrm{ha}^{-1}$ as compared to District average productivity of $22.5 \mathrm{qt} \mathrm{ha}^{-1}$. Average input cost of cultivation was Rs 15127.68 $\mathrm{ha}^{-1}$ and outcome was Rs 42796.25 $\mathrm{ha}^{-1}$ and benefit cost ratio increases from 2.1 to 2.72 .

In conclusion, from the study carried out following conclusions can be drawn for SRI in the district:

Mechanization increases little input cost but it significantly increases productivity of Paddy in Systems of Rice Intensification (SRI).

Small farm implements and Machines i.e., Power Tiller, Marker and Cono Weeder plays very imperative role in enhancement of productivity and reduction of drudgery in SRI.

In SRI system plant to plant and row to row equi- distance is not possible by rope but Jawahar Paddy Plant Marker is a very efficient implement for marking $25 \times 25 \mathrm{~cm}$ grids in well puddled field and Cono weeder can work without difficulty in horizontal and vertical direction.

Power tiller is a better machine for puddling in paddy field as compared with cultivator and Deshi Plough.
Controlled irrigation and drainage facility is very essential in SRI.

\section{References}

Chaturvedi, et al., (2006) Peoples Science Institute, Dehradoon, SRI Report doc pp 25-27 (On line).

Gulsan M and Sarao P S, (2009) J.Res. ANGRAU 37(1\&2): 1-6,

Lin XQ, Zhou WJ, Zhu DF (2005). The photosynthetic rate and water use efficiency of leaves at different position at panicle initiation stage under the System of Rice Intensification (SRI). Chinese J. Rice Sci., 1(9): 200-206.

Ravi, G., Rajendran, R., Raju, N., Murlidharan, V., Chandrasekaran, B and Balasubramanian, V. (2006). Impact of System of Rice Intensification (SRI) on insect pests and arthropod biodiversity: A case study in irrigated rice ecosystem. In: 26th International Rice Congress, Oct. 9-13, New Delhi, pp. 421-422.

Satyanarayana, et al., (2006), Case study 1, unbelievable tillering capacity Taking Roots, ANGARU Hyderabad, pp 7-42 (on line).

Wang, S., Cao, W., Jiang, D., Dai, T and ZHU, (2002) Physiological characteristics and high yield technique for SRI rice. In Assessment of the SRI: Proceeding of an International Conference, Sanya, China, April, 1-4, 2002, 116-124.

\section{How to cite this article:}

Ghanshyam Deshmukh, S.L. Alawa and Jhade, R.K. 2019. Introduction of System of Rice Intensification (SRI) in Tribal Area of Chhindwara of (M.P). Int.J.Curr.Microbiol.App.Sci. 8(04): 891-894. doi: https://doi.org/10.20546/ijcmas.2019.804.101 